www.nature.com/leu

\title{
ERRATUM
}

\section{Dexrazoxane has no impact on sensitivity of childhood leukemic blasts to daunorubicin}

J Styczynski, M Wysocki, W Balwierz and JR Kowalczyk

\author{
Correction to: Leukemia (2002) 16, 820-825. \\ doi:10.1038/sj.leu.2402474 \\ Leukemia (2002) 16, 2346. doi:10.1038/sj.leu.2402659 \\ In the above paper the affiliation of M Wysocki is mistakenly \\ quoted as being ${ }^{2}$. The correct affiliation should have been ${ }^{1}$.
}

${ }^{1}$ Department of Pediatric Hematology and Oncology, Medical Univer-
sity, Bydgoszcz, Poland 